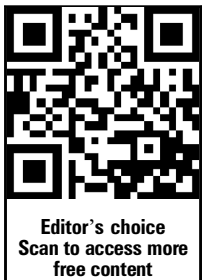

free content

\begin{abstract}
- Additional material is published online only. To view please visit the journal online (http://dx.doi.org/10.1136/ oemed-2013-101482).

${ }^{1}$ Department of Public Health Sciences and Queen's Cancer Research Institute, Queen's University, Kingston, Ontario, Canada

${ }^{2}$ Department of Environmental and Occupational Health,

School of Public Health, Drexel University, Philadelphia,

Pennsylvania, USA

${ }^{3}$ Department of Cancer Control Research, British Columbia Cancer Agency, Vancouver, British Columbia, Canada

${ }^{4}$ Department of Pathology and Molecular Medicine, Queen's University, Kingston, Ontario, Canada

${ }^{5}$ School of Population and Public Health, University of British Columbia, Vancouver, British Columbia, Canada
\end{abstract}

\section{Correspondence to}

Dr Kristan J Aronson, Division of Cancer Care and Epidemiology, Queen's Cancer Research Institute, 10 Stuart Street, Kingston, Ontario,

Canada K7L 3N6;

aronson@queensu.ca

Received 5 March 2013 Revised 6 May 2013 Accepted 15 May 2013 Published Online First 01 July 2013

\section{SLinked}

- http://dx.doi.org/10.1136/ oemed-2013-101630

To cite: Grundy A Richardson H, Burstyn I, et al. Occup Environ Med 2013;70:831-838.

\title{
Increased risk of breast cancer associated with long-term shift work in Canada
}

\author{
Anne Grundy, ${ }^{1}$ Harriet Richardson, ${ }^{1}$ Igor Burstyn, ${ }^{2}$ Caroline Lohrisch, ${ }^{3}$ \\ Sandip K SenGupta, ${ }^{4}$ Agnes S Lai, ${ }^{3}$ Derrick Lee, ${ }^{3}$ John J Spinelli, ${ }^{3,5}$ Kristan J Aronson $^{1}$
}

ABSTRACT
Objectives Long-term night work has been suggested as a risk factor for breast cancer; however, additional studies with more comprehensive methods of exposure assessment to capture the diversity of shift patterns are needed. As well, few previous studies have considered the role of hormone receptor subtype.

Methods Relationships between night shift work and breast cancer were examined among 1134 breast cancer cases and 1179 controls, frequency-matched by age in Vancouver, British Columbia, and Kingston, Ontario. Self-reported lifetime occupational histories were assessed for night shift work, and hormone receptor status obtained from tumour pathology records.

Results With approximately one-third of cases and controls ever employed in night shift work, associations with duration demonstrated no relationship between either $0-14$ or 15-29 years, while an association was apparent for $\geq 30$ years $(O R=2.21,95 \% \mathrm{Cl} 1.14$ to 4.31). This association with long-term night shift work is robust to alternative definitions of prolonged shift work, with similar results for both health and non-health care workers.

Conclusions Long-term night shift work in a diverse mix of occupations is associated with increased breast cancer risk and not limited to nurses, as in most previous studies.

\section{INTRODUCTION}

Night shift work has been suggested as risk factor for several cancer sites, ${ }^{1-4}$ and in 2007, the International Agency for Research on Cancer (IARC) classified shift work involving circadian disruption as a probable carcinogen ${ }^{5} 6$ on the basis of 'sufficient evidence' in experimental models and 'limited evidence' in humans. Most epidemiologic studies have focused on relationships with breast cancer, where results from meta-analyses demonstrate a $40-50 \%$ increase in breast cancer risk associated with long-term (at least 20-30 years) night shift work. ${ }^{2} 3$ While the biological mechanism linking night shift work with cancer risk remains unknown, the main hypothesised pathway involves melatonin. ${ }^{7} 8$ Melatonin, a pineal hormone that is inhibited by light and considered a biomarker of chronodisruption, has also been suggested to have several cancer-protective properties. ${ }^{9}$ While increased light exposure during night shifts is thought to decrease production of melatonin, thereby increasing cancer risk, other mechanisms are also possible. ${ }^{6}$

\section{What this paper adds}

- Shift work has been suggested as a risk factor for breast cancer; however, studies are needed with better exposure assessment methods that capture the diversity of shift patterns worked.

- Several previous studies have been restricted to nurses, and few have considered the impact of tumour hormone receptor status.

- This large study demonstrated an association between 30 or more years of shift work and breast cancer, with no interaction by tumour hormone receptor status, and is one of only a few studies to demonstrate this relationship in a sample from the general population.

Some studies have reported a modest statistically significant increase in risk of some cancer sites among long-term night shift workers, ${ }^{10-19}$ but others have not. ${ }^{20-23}$ Definitions of night shift work have been varied, and improved exposure assessment has been recommended by a 2009 IARC Working Group. ${ }^{24}$ Studies using job-exposure matrix-based methods to assess night shift work $^{11} 142123$ may be prone to exposure classification errors, as some individuals within night shift work job-classification groups may not have actually been exposed, even if the majority of individuals in their profession are engaged in night shift work. ${ }^{24}$ Other studies that have used questions at the individual level have the advantage of exposure information specific to individual participants, ${ }^{12} 13 \quad 15$ 2022 but may be limited by misclassification if the night shift work that has been performed does not meet the exact definition provided in the question. ${ }^{24}$ Several studies with individual-level measures of night shift work have been limited to nurses ${ }^{12-16}$ and it is not clear if associations between night shift work and breast cancer consistently extend beyond this occupational group.

Consideration of breast tumour oestrogen/progesterone receptor (ER)/(PR) status in relationships with night shift work has been rare. ${ }^{12} 20$ This may be important since differences in aetiology have been suggested for hormone receptor positive and negative tumours, since the effects of several breast cancer risk factors, such as parity and age at first birth vary between tumour groups. ${ }^{25-27}$ Further, melatonin may influence risk through an increase in oestrogen production, ${ }^{28}$ such that a stronger 
relationship for hormone-dependent tumours might be expected. The objective of this research was to test a hypothesis that an increased risk of breast cancer in women is associated with long-term night shift work in the general population, to test the robustness of associations by various definitions of night shift work, to assess risk in different occupational groups, and to determine if risk varied by hormone receptor status.

\section{METHODS}

\section{Study population}

A case-control study was conducted in Vancouver, British Columbia (BC) and Kingston, Ontario, from 2005 to 2010.

\section{Vancouver}

Incident breast cancer cases were recruited from the BC Cancer Registry. Eligible cases were women, aged $20-80$ years, with a diagnosis of either in situ or invasive breast cancer with no previous cancer history (except non-melanoma skin cancer) living in Vancouver, New Westminster, Richmond and Burnaby. Potential controls were cancer-free individuals from the Screening Mammography Program of BC recruited from breast screening clinics in the same geographic areas who consented to participate in research studies through routine screening mammography (available to women in BC aged 40-79 years). Controls were frequency-matched to cases by 5 -year age group. All potential participants received a study package including a letter describing the study, a consent form, and a study questionnaire. Participation involved completing the questionnaire, either self-administered or collected by telephone interview, in English, Cantonese, Mandarin or Punjabi, providing a blood sample and granting access to medical records concerning breast health. Response rates were 54\% among cases and 57\% among controls, with a total of 1055 cases and 1016 controls recruited. However, as the minimum age for screening mammography in $\mathrm{BC}$ is 40 years, all cases diagnosed under the age of 40 years were excluded. Following these exclusions, 1003 cases and 1015 controls from Vancouver were included in the analysis.

\section{Kingston}

Both, cases and controls, were recruited from the Hotel Dieu Breast Assessment Program in Kingston, Ontario. Women were eligible for the study if they were under 80 years of age, had no previous cancer history (except non-melanoma skin cancer), were not too ill to participate, and were not taking cancerpreventative drugs. Those consenting to be contacted were called by the study coordinator to confirm eligibility, and sent a package including study information, questionnaire and consent form. Cases were women with a subsequent diagnosis of either in situ or invasive breast cancer, while controls were women with either normal mammogram results or a diagnosis of benign breast disease, frequency matched by age as in Vancouver. Among those contacted, response rates were 59\% among cases and $49 \%$ among controls, with a total of 131 cases and 164 controls included. Study participation involved the same process as in Vancouver, although in Kingston all participants selfadministered the questionnaire.

\section{Procedures}

The questionnaire contained information regarding education, ethnicity, health, medical and reproductive history, family history of cancer, lifestyle characteristics including lifetime tobacco and alcohol consumption, lifetime physical activity and lifetime occupational and residential histories.
Night shift work exposure assessment

Lifetime exposure to night shift work was obtained from the occupational history. For any job held for at least 6 months, participants provided the industry and job title, start and end dates, average number of hours per week, percentage of time on day, evening and night shifts (as a continuous variable), as well as start and end times for each shift type. This information was used to categorise each job as either a 'night shift' or 'non-night shift' occupation. For the 'main' analyses, night shift work jobs were classified as those where $\geq 50 \%$ of time was reported to have been spent on evening and/or night shifts, capturing both rotating and permanent night shift schedules. The total number of years spent employed in all 'night shift' jobs was calculated for each individual. The influence of the proportion of evening and late night shifts required for a job to be considered 'night shift work' was investigated with definitions of $20,40,60,80$ and $100 \%$, compared with the 50\% used in the main analysis. An additional night shift work metric involving the use of start and end times of shifts, where those jobs including shifts that started or ended between 23:00 and 7:00 were considered night shift jobs, was also evaluated.

For the overall and postmenopausal analysis, duration of night shift work was classified into four categories: none, $>0-14$, 15-29 and $\geq 30$ years. ${ }^{12-14}$ Among premenopausal women, categories were: none, $>0-9,10-19$ and $\geq 20$ years. ${ }^{13}$ As well, duration of night shift work was split into eight categories of 5 -year increments to further investigate the impact of the broader categorisations used in the main analysis.

To further describe the types of jobs performed, the selfreported industry for the job that each individual held for the longest period of time was classified according to the Statistics Canada National Occupational Classification $2006^{29}$ into one of 10 categories. For women with a history of night shift work, the job they had held for the longest period of time that met the criteria for a 'night shift' job was classified.

\section{Breast tumour biomarker assessment}

Pathologic data concerning tumour ER and PR biomarker status was collected for all breast cancer cases. In Vancouver, this information was obtained from the BC Cancer Registry and BC Breast Cancer Outcomes Unit and in Kingston was obtained directly from electronic patient charts. ER status was determined from immunohistochemistry (IHC) results and classified into one of six categories: negative, weakly positive, moderately positive, strongly positive, receptors tested but not sufficient quantity for interpretation or borderline/equivocal and not tested. Tumours were considered ER positive if they were classified as weakly, moderately or strongly positive. PR status was also determined through IHC testing using the same categorisations as the ER analysis.

\section{Assessment of menopausal status}

The relationship between night shift work and breast cancer risk was also examined stratified by menopausal status. Women were classified as postmenopausal if they: stated menstruation had stopped for greater than 1 year; menstruation stopped naturally and they were over 50 years of age if time since last menstruation was missing; had a bilateral oophrectomy; or they were over age 55 years and menstruation stopped due to chemotherapy or other reasons, similar to Friedenreich et al. ${ }^{30}$ A total of 836 women were premenopausal and 1471 were postmenopausal. 


\section{Statistical analysis}

Multivariable unconditional logistic regression was used to calculate ORs and 95\% CIs for the relationship between night shift work and breast cancer risk. Age (continuous) and centre (Vancouver/Kingston) were included in all models, and all other variables were selected using an all-possible-models manual backwards selection procedure, ${ }^{31}$ where potential confounders associated with breast cancer at $\mathrm{p}<0.25$ were initially included in the modelling process, and only variables that changed the OR by $>10 \%$ were retained in the final model. Potential confounders were ethnicity; household income; education; menopausal status; use of fertility drugs, oral contraceptives, non-steroidal antiinflammatory drugs (NSAIDs), antidepressants and hormone replacement therapy (HRT); reproductive factors including ever having been pregnant, number of pregnancies, age at first birth, breastfeeding and age at first mammogram; family history of breast cancer among first-degree relatives; lifestyle factors, including smoking status, pack-years smoking and lifetime alcohol consumption; and body mass index (BMI). Tests for trends across night shift work categories were calculated by treating levels of exposure as a continuous ordinal variable, and possible interactions by menopausal status were assessed by including a night shift work/menopausal status interaction term. Multivariable polytomous logistic regression was used to evaluate the breast cancer risk associated with night shift work history by hormone receptor status in one of two categories, as either ER and/or PR positive, or negative. Cases where both ER and PR status were either not tested or missing were excluded $(n=129)$. Among excluded cases, 90 (70\%) were cases of ductal carcinoma in situ, in which testing of ER and PR tumour status is not routine. A total of $76(84 \%)$ in situ cases were explicitly classified as not tested, compared with seven (21\%) of invasive cases.

Since controls in Vancouver were obtained from a screening population, while cases came from the population-based BC Cancer Registry, a sensitivity analysis was performed excluding cases that did not participate in screening. Cases from Vancouver were linked to the Screening Mammography Program of BC using provincial personal health numbers, and those that had not been seen in the screening program were excluded $(n=255)$. As well, an analysis stratified by ethnicity (European versus Asian) was also conducted to further examine the influence of ethnicity on observed results. Finally, as BMI was a confounder in both models when the analysis was stratified by menopausal status, an analysis including BMI, menopausal status and a BMI $\times$ menopausal status interaction term was conducted to investigate whether these variables would confound night shift work/breast cancer relationships when this potential joint effect was included.

\section{RESULTS}

Characteristics of cases and controls are described in table 1. The case group included a smaller proportion of Europeans and a greater proportion of Asians than the control group. Further, cases had lower levels of household income and education, were less likely to have used NSAIDs and oral contraceptives, were more likely to have ever been pregnant, had an older average age of first mammogram, were more likely to have a family history of breast cancer among first-degree relatives, and had lower levels of lifetime alcohol consumption compared with controls. These variables were considered as potential confounders in multivariate models.

Approximately one-third of both cases and controls (table 2) had a history of night shift work. Proportions of cases and controls were similar in the $0-14$ (minimum $=3$ months) and 15-29 years of night shift work categories, while the proportion of cases in the $\geq 30$ (maximum $=47$ ) years night shift work category was higher than in the control group. These patterns were maintained in multivariate analysis (table 2) where no association between night shift work and breast cancer risk was observed for either the $0-14$ and 15-29-year categories, while an association with $\geq 30$ years night shift work was observed. However, no statistically significant trend across categories of night shift work was noted. Ethnicity, household income, education, menopausal status, NSAID and oral contraceptive use, family history, age at first mammogram, ever having been pregnant, breastfeeding, lifetime history of alcohol consumption and BMI were considered as potential confounders, although none changed estimated ORs by $>10 \%$ and, thus, were not retained in the final multivariate model. Among postmenopausal women, results were similar to the overall analysis, with the largest estimated OR seen in the $\geq 30$ years night shift work category, although the OR is smaller than that seen in the overall analysis, and the CI did include 1.0 (table 2). As well, night shift work did appear protective in the $0-14$ years category in postmenopausal women and among premenopausal women, no relationship between any night shift work category and breast cancer was observed.

Results from sensitivity analysis excluding non-screened cases were similar to those from the full study population where no association was observed for either the $0-14(\mathrm{OR}=0.94,95 \%$ CI 0.77 to 1.16$)$ or $15-29$ years $(\mathrm{OR}=0.97,95 \%$ CI 0.68 to 1.38) night shift work categories and a positive association was seen in the $\geq 30$ years night shift work category $(\mathrm{OR}=2.23$, $95 \%$ CI 1.12 to 4.45 ). As well, results from stratified analysis of Europeans and Asians were similar to both each other and the main analysis, with highest ORs seen for the $\geq 30$ years category (see online supplementary table S1). Similar patterns to the main analysis were also seen when in situ breast cancer cases were excluded, with a positive association observed in the $\geq 30$ years night shift work category (see online supplementary table S1). Finally, when BMI, menopausal status and a BMI $\times$ menopausal status interaction term were included in the overall model results were similar to the original overall analysis (see online supplementary table S1).

When the influence of the proportion of evening and late night shifts required for a job to be considered 'night shift work' was examined, no association for either short-term (014 years) or medium-term (15-29 years) night shift work was observed, while the OR between night shift work and breast cancer in the long-term night shift work ( $\geq 30$ years) category generally increased as the cut-point increased (table 3). However, due to small numbers in the most extreme category, precision declined substantially for estimates of long-term night shift work for thresholds over 50\%. When duration of exposure to night shift work was split into eight categories of 5-year increments, as in the main analysis, no association between any duration of night shift work under 30 years and breast cancer was observed (table 3). When night shift work exposure was characterised using shift start and end times, the OR remained highest in the $\geq 30$ years category, although the CI did include 1.0. ORs for other night shift work categories were elevated compared with the main analysis, where the CI for the 0 14 years category no longer included 1.0 (table 3). However, data on shift start/stop times was missing for 145 (6.3\%) participants.

When examining the influence of tumour ER/PR biomarker status on the relationship between night shift work history and 
Table 1 Characteristics of study population

\begin{tabular}{|c|c|c|c|c|}
\hline & $\begin{array}{l}\text { Cases }(n=1134) \\
\text { Mean }(S D) / n(\%)\end{array}$ & $\begin{array}{l}\text { Controls }(n=1179) \\
\text { Mean (SD)/n (\%) }\end{array}$ & $\begin{array}{l}\text { Never night shift workers }(n=1524) \\
\text { Mean }(\text { SD)/n }(\%)\end{array}$ & $\begin{array}{l}\text { Ever night shift workers }(\mathrm{n}=789) \\
\text { Mean }(\mathrm{SD}) / \mathrm{n}(\%)\end{array}$ \\
\hline Age & $57.30(10.3)$ & $56.72(10.0)$ & $58.0(10.3)$ & $55.1(9.6)$ \\
\hline Body mass index & $25.68(5.5)$ & $25.28(5.8)$ & $25.3(5.4)$ & $25.8(6.2)$ \\
\hline \multicolumn{5}{|l|}{ Ethnicity } \\
\hline European & 707 (62.4) & $921(78.3)$ & $1043(68.5)$ & $585(74.2)$ \\
\hline Chinese & $239(21.1)$ & $114(9.7)$ & $262(17.2)$ & $91(11.6)$ \\
\hline South Asian & $34(3.0)$ & $35(3.0)$ & $55(3.6)$ & $14(1.8)$ \\
\hline Filipino & $60(5.3)$ & $38(3.2)$ & $57(3.7)$ & $41(5.2)$ \\
\hline Japanese & $24(2.1)$ & $14(1.2)$ & $23(1.5)$ & $15(1.9)$ \\
\hline Mixed & $19(1.7)$ & $12(1.0)$ & $17(1.1)$ & $14(1.8)$ \\
\hline Other & $51(4.5)$ & $43(3.7)$ & $66(4.3)$ & $28(3.5)$ \\
\hline \multicolumn{5}{|l|}{ Household income } \\
\hline$<\$ 30000$ & $203(17.9)$ & $121(10.3)$ & $217(14.2)$ & 107 (13.6) \\
\hline$\$ 30000-\$ 59999$ & $279(24.6)$ & $269(22.8)$ & $355(23.3)$ & $193(24.5)$ \\
\hline$\$ 60000-\$ 99999$ & $245(21.6)$ & $288(24.4)$ & $334(21.9)$ & $199(25.2)$ \\
\hline$>\$ 100000$ & $238(21.0)$ & $339(28.8)$ & $372(24.4)$ & $205(26.0)$ \\
\hline Not stated & $169(14.9)$ & $162(13.8))$ & $246(16.1)$ & $85(10.9)$ \\
\hline \multicolumn{5}{|l|}{ Education } \\
\hline High school or less & $392(34.8)$ & $300(25.5)$ & $499(33.0)$ & $193(24.5)$ \\
\hline College/trade certificate & $344(30.6)$ & $349(29.7)$ & $434(28.7)$ & 259 (32.9) \\
\hline Undergraduate degree & $264(23.5)$ & $302(25.7)$ & $356(23.5)$ & $210(26.7)$ \\
\hline Graduate/professional degree & $126(11.2)$ & $225(19.1)$ & $225(14.9)$ & $126(16.0)$ \\
\hline \multicolumn{5}{|l|}{ Menopausal status } \\
\hline Premenopausal & 391 (34.6) & $445(37.8)$ & $492(32.4)$ & $344(43.7)$ \\
\hline Postmenopausal & $739(65.4)$ & $732(62.2)$ & $1028(67.6)$ & $443(56.3)$ \\
\hline \multicolumn{5}{|l|}{ Medication use } \\
\hline Fertility drugs (ever/never) & $63(5.6)$ & $64(5.4)$ & $86(5.7)$ & $41(5.2)$ \\
\hline \multicolumn{5}{|l|}{ Number of years NSAID use } \\
\hline None & $994(87.7)$ & $992(84.1)$ & $1328(87.1)$ & $658(83.4)$ \\
\hline$<2.34$ & $55(4.9)$ & $62(5.3)$ & $69(4.5)$ & $48(6.1)$ \\
\hline $2.34-8.50$ & $48(4.2)$ & $61(5.2)$ & $72(4.7)$ & $37(5.0)$ \\
\hline$\geq 8.51$ & $37(3.3)$ & $64(5.4)$ & $55(3.6)$ & $46(5.8)$ \\
\hline \multicolumn{5}{|l|}{ Number of years oral contraceptive use } \\
\hline None & $558(49.2)$ & $429(36.4)$ & $695(45.6)$ & $292(37.0)$ \\
\hline$<4.50$ & $192(16.9)$ & $248(21.0)$ & $277(18.2)$ & $163(20.7)$ \\
\hline $4.50-10.00$ & $215(19.0)$ & $276(23.4)$ & $317(20.8)$ & $174(22.1)$ \\
\hline$\geq 10.01$ & $169(14.9)$ & $226(19.2)$ & $235(15.4)$ & $160(20.3)$ \\
\hline \multicolumn{5}{|l|}{ Number of years antidepressant use } \\
\hline None & $911(80.3)$ & $916(77.8)$ & $1229(80.7)$ & $598(75.8)$ \\
\hline$<1.50$ & $74(6.5)$ & $86(7.3)$ & $102(6.7)$ & $58(7.4)$ \\
\hline $1.50-7.50$ & $87(7.7)$ & $87(7.4)$ & $95(6.2)$ & $79(10.0)$ \\
\hline$\geq 7.51$ & $62(5.5)$ & $89(7.6)$ & $97(6.4)$ & $54(6.8)$ \\
\hline \multicolumn{5}{|l|}{ Number of years HRT use } \\
\hline None & $833(73.5)$ & $854(72.4)$ & $1112(73.0)$ & $575(72.9)$ \\
\hline$<5.00$ & $91(8.0)$ & $99(8.4)$ & $120(7.9)$ & $70(8.9)$ \\
\hline $5.00-12.00$ & $114(10.1)$ & $120(10.2)$ & $156(10.2)$ & $78(9.9)$ \\
\hline$\geq 12.01$ & $96(8.5)$ & $106(9.0)$ & $136(8.9)$ & $66(8.4)$ \\
\hline \multicolumn{5}{|l|}{ Reproductive history } \\
\hline Age at menarche & $12.89(1.6)$ & $12.84(1.5)$ & $12.9(1.5)$ & $12.7(1.6)$ \\
\hline Ever been pregnant & $937(82.9)$ & $937(79.6)$ & $1234(81.2)$ & $640(81.3)$ \\
\hline Age at first pregnancy* & $27.69(5.4)$ & $27.54(5.3)$ & $27.6(5.4)$ & $27.6(5.4)$ \\
\hline Breastfeeding (number of months) & $6.9(9.8)$ & $7.9(10.4)$ & $7.1(10.0)$ & $7.9(10.5)$ \\
\hline Number of pregnancies* & $2.28(1.7)$ & $2.25(1.7)$ & $2.3(1.7)$ & $2.3(1.7)$ \\
\hline Age at first mammogram & $44.72(8.8)$ & $42.78(7.5)$ & $44.4(8.5)$ & $42(7.6)$ \\
\hline Family history of breast cancer & $223(19.7)$ & $168(14.3)$ & $267(17.5)$ & $124(15.7)$ \\
\hline \multicolumn{5}{|l|}{ Lifestyle characteristics } \\
\hline Current smoker & $72(6.4)$ & $71(6.0)$ & $89(5.9)$ & $54(6.9)$ \\
\hline Pack-years smoking & $5.64(12.1)$ & $5.29(11.2)$ & $5.3(11.8)$ & $5.7(11.5)$ \\
\hline
\end{tabular}


Table 1 Continued

\begin{tabular}{lllcc}
\hline & $\begin{array}{l}\text { Cases }(\mathbf{n}=1134) \\
\text { Mean }(\mathbf{S D}) / \mathbf{n}(\%)\end{array}$ & $\begin{array}{l}\text { Controls }(\mathbf{n}=1179) \\
\text { Mean }(\mathrm{SD}) / \mathbf{n}(\%)\end{array}$ & $\begin{array}{l}\text { Never night shift workers }(\mathbf{n}=1524) \\
\text { Mean }(\mathbf{S D}) / \mathbf{n}(\%)\end{array}$ & $\begin{array}{l}\text { Ever night shift workers }(\mathbf{n}=\mathbf{7 8 9}) \\
\text { Mean }(\mathrm{SD}) / \mathbf{n}(\%)\end{array}$ \\
\hline Teen & $1.05(3.5)$ & $1.63(4.0)$ & $1.1(3.1)$ & $1.9(4.7)$ \\
$20 \mathrm{~s}$ & $2.24(3.9)$ & $3.26(6.1)$ & $2.5(5.2)$ & $3.3(5.0)$ \\
$30 \mathrm{~s}$ & $2.91(6.0)$ & $3.61(5.8)$ & $3.0(5.6)$ & $3.7(6.4)$ \\
$40 \mathrm{~s}$ & $3.10(6.0)$ & $3.75(6.1)$ & $3.3(6.2)$ & $3.6(5.7)$ \\
$50 \mathrm{~s}$ & $2.76(4.9)$ & $3.71(6.1)$ & $3.2(5.6)$ & $3.3(5.3)$ \\
\hline
\end{tabular}

${ }^{*}$ Among parous women only.

breast cancer, the proportions of women with no history of shift work were similar across tumour subgroups (table 4), and no association between 0-14 years and 15-29 years of night shift work and breast cancer risk was seen for either breast cancer subgroup. While the OR for the association for $\geq 30$ years of night shift work was stronger in the ER/PR+ subgroup, no interaction by hormone receptor biomarker status was detected (table 4) and the number of ER/PR- cases was quite small.

The industry of the job held for the longest period of time was classified into one of 10 categories for women in each of the four night shift work history groups (table 5) to classify the types of jobs held by women who did and did not engage in night shift work. This demonstrated that the largest proportion were employed in health occupations such as nursing in both the $\geq 30$ years $(44 \%)$ and $15-29$ years (41\%) night shift work groups, while the proportions in this industry in the $0-14$ years (19\%) and never night shift worker (10\%) groups were lower. Finally, to investigate the influence of job type, associations between night shift work and breast cancer were investigated for women employed in health occupations only. Similar patterns were observed for both health and non-health occupations, where, as in the main analysis, no association was observed for the 0-14 years and 15-29 years night shift work categories, while increased breast cancer risk was observed among women working $\geq 30$ years of night shift work (table 2).

\section{DISCUSSION}

The study demonstrated an increased breast cancer risk among women employed in night shift work for $\geq 30$ years across several occupations, with no association seen for shorter

Table 2 Shift work history and breast cancer risk

\begin{tabular}{|c|c|c|c|c|c|}
\hline Years shift work history* & $\begin{array}{l}\text { Cases } \\
\mathbf{n}(\%)\end{array}$ & $\begin{array}{l}\text { Controls } \\
\mathrm{n}(\%)\end{array}$ & OR & $95 \% \mathrm{Cl}$ & $\begin{array}{l}\text { Interaction by } \\
\text { menopausal status }\end{array}$ \\
\hline \multicolumn{6}{|l|}{ Overallt } \\
\hline None & $751(66.2)$ & $773(65.6)$ & - & & \\
\hline $0-14$ & $283(25.0)$ & $312(26.5)$ & 0.95 & 0.79 to 1.16 & $p=0.01$ \\
\hline $15-29$ & $72(6.3)$ & $81(6.9)$ & 0.93 & 0.67 to 1.30 & $p=0.7$ \\
\hline \multirow[t]{2}{*}{$\geq 30$} & $28(2.5)$ & $13(1.1)$ & 2.21 & 1.14 to 4.31 & $p=0.2$ \\
\hline & & & & $\mathrm{p}$-trend $=0.5$ & \\
\hline \multicolumn{6}{|l|}{ Postmenopausalł } \\
\hline None & $531(71.5)$ & $501(68.3)$ & - & & \\
\hline $0-14$ & $142(19.1)$ & $175(23.8)$ & 0.75 & 0.58 to 0.97 & \\
\hline $15-29$ & $48(6.5)$ & $46(6.3)$ & 0.97 & 0.63 to 1.49 & \\
\hline \multirow[t]{2}{*}{$\geq 30$} & $22(3.0)$ & 12 (1.6) & 1.63 & 0.80 to 3.35 & \\
\hline & & & & $p$-trend $=0.8$ & \\
\hline \multicolumn{6}{|l|}{ Premenopausal‡ } \\
\hline None & $220(56.3)$ & $272(61.1)$ & - & & \\
\hline $0-9$ & $126(32.2)$ & $119(26.7)$ & 1.32 & 0.97 to 1.80 & \\
\hline $10-19$ & $27(6.9)$ & $35(7.9)$ & 0.99 & 0.57 to 1.70 & \\
\hline \multirow[t]{2}{*}{$\geq 20$} & $18(4.6)$ & $19(4.3)$ & 1.30 & 0.66 to 2.58 & \\
\hline & & & & $\mathrm{p}$-trend $=0.3$ & \\
\hline \multicolumn{6}{|l|}{ Health occupations } \\
\hline None & $62(44.9)$ & $94(5.0)$ & - & & \\
\hline $0-14$ & $38(27.5)$ & $72(34.4)$ & 0.80 & 0.48 to 1.33 & \\
\hline $15-29$ & $26(18.8)$ & $37(17.7)$ & 1.06 & 0.58 to 1.92 & \\
\hline$\geq 30$ & $12(8.7)$ & $6(2.9)$ & 3.11 & 1.10 to 8.77 & \\
\hline \multicolumn{6}{|l|}{ Non-health occupations } \\
\hline None & $689(69.2)$ & $679(70.0)$ & - & & \\
\hline $0-14$ & $245(24.6)$ & $240(24.7)$ & 1.04 & 0.84 to 1.29 & \\
\hline $15-29$ & $46(4.6)$ & $44(4.5)$ & 1.06 & 0.69 to 1.62 & \\
\hline$\geq 30$ & $16(1.6)$ & $7(0.7)$ & 2.25 & 0.92 to 5.52 & \\
\hline
\end{tabular}


Table 3 Additional shift work categorisations

\begin{tabular}{|c|c|c|c|c|}
\hline Variable & $\begin{array}{l}\text { Cases }(n=1142) \\
\text { Mean }(S D \%)\end{array}$ & $\begin{array}{l}\text { Controls }(n=1178) \\
\text { Mean }(S D \%)\end{array}$ & OR & $95 \% \mathrm{Cl}$ \\
\hline \multicolumn{5}{|l|}{$20 \%$ Evening or night shifts* } \\
\hline None & $610(53.8)$ & $618(52.4)$ & - & \\
\hline$<15$ & $338(29.8)$ & $352(29.9)$ & 1.00 & 0.83 to 1.21 \\
\hline $15-30$ & $129(11.4)$ & $160(13.6)$ & 0.83 & 0.64 to 1.07 \\
\hline$\geq 30$ & $57(5.0)$ & $49(4.2)$ & 1.18 & $0.79-1.76$ \\
\hline \multicolumn{5}{|l|}{$40 \%$ Evening or night shifts* } \\
\hline None & $720(63.5)$ & $752(63.8)$ & - & \\
\hline$<15$ & $298(26.3)$ & $316(26.8)$ & 1.01 & 0.83 to 1.22 \\
\hline $15-30$ & $86(7.6)$ & $95(8.1)$ & 0.96 & 0.70 to 1.31 \\
\hline$\geq 30$ & $30(2.7)$ & $16(1.4)$ & 1.97 & 1.06 to 3.65 \\
\hline \multicolumn{5}{|l|}{$60 \%$ Evening or night shifts* } \\
\hline None & $876(77.3)$ & $903(76.6)$ & - & \\
\hline$<15$ & $200(17.6)$ & $228(19.3)$ & 0.93 & 0.75 to 1.15 \\
\hline $15-30$ & $40(3.5)$ & $42(3.6)$ & 0.98 & 0.63 to 1.53 \\
\hline$\geq 30$ & $18(1.6)$ & $6(0.5)$ & 3.09 & 1.22 to 7.84 \\
\hline \multicolumn{5}{|l|}{$80 \%$ Evening or night shifts* } \\
\hline None & $941(83.0)$ & $974(82.6)$ & - & \\
\hline$<15$ & $162(14.3)$ & $181(15.4)$ & 0.95 & 0.75 to 1.20 \\
\hline $15-30$ & $20(1.8)$ & $21(1.8)$ & 0.98 & 0.53 to 1.82 \\
\hline$\geq 30$ & $11(1.0)$ & $3(0.3)$ & 3.73 & 1.04 to 13.42 \\
\hline \multicolumn{5}{|l|}{$100 \%$ Evening or night shifts* } \\
\hline None & $976(86.1)$ & $1029(87.3)$ & - & \\
\hline$<15$ & $136(12.0)$ & $139(11.8)$ & 1.05 & 0.82 to 1.35 \\
\hline $15-30$ & $17(1.5)$ & $9(0.8)$ & 1.93 & 0.86 to 4.36 \\
\hline$>30$ & $5(0.4)$ & $2(0.2)$ & 2.63 & 0.51 to 13.64 \\
\hline \multicolumn{5}{|l|}{5 Year shift work segments (using $50 \%$ of time definition)* } \\
\hline None & $751(66.2)$ & $773(65.6)$ & - & \\
\hline $0-4$ & $160(14.1)$ & $142(12.1)$ & 1.18 & 0.92 to 1.52 \\
\hline $5-9$ & $85(7.5)$ & $119(10.1)$ & 0.75 & 0.56 to 1.01 \\
\hline $10-14$ & $38(3.4)$ & $51(4.3)$ & 0.79 & 0.51 to 1.22 \\
\hline $15-19$ & $30(2.7)$ & $34(2.9)$ & 0.93 & 0.56 to 1.54 \\
\hline $20-24$ & $26(2.3)$ & $27(2.3)$ & 1.01 & 0.59 to 1.75 \\
\hline $25-29$ & $16(1.4)$ & $20(1.7)$ & 0.82 & 0.42 to 1.59 \\
\hline $30-34$ & $14(1.2)$ & $7(0.6)$ & 2.05 & 0.82 to 5.11 \\
\hline$\geq 35$ & $14(1.2)$ & $6(0.5)$ & 2.40 & 0.92 to 6.30 \\
\hline Number of years in jobs with shifts starting or ending between $11 \mathrm{PM}$ and $7 \mathrm{AM}+$ & $(\mathrm{N}=1063)$ & $(\mathrm{N}=1105)$ & & \\
\hline None & $826((77.7)$ & $906(82.0)$ & & \\
\hline$<15$ & $172(15.2)$ & $146(12.4)$ & 1.29 & 1.01 to 1.65 \\
\hline $15-30$ & $49(4.3)$ & $43(3.7)$ & 1.27 & 0.83 to 1.95 \\
\hline$\geq 30$ & $16(1.4)$ & $10(0.9)$ & 1.68 & 0.74 to 3.79 \\
\hline
\end{tabular}

durations and no interaction with hormone receptor status apparent. Similar to other case-control studies conducted in the general population, ${ }^{10} 2022$ the majority of both cases and controls in this study had not participated in any type of night shift work, and only a small proportion had been engaged in night shift work for 30 years or more.

One study strength was its use of a lifetime occupational history for participants to record the proportion of day, evening and night shifts for each job, allowing jobs with both rotating and permanent night shift patterns to be captured in a single definition of night shift work. This is an improvement over some previous nested case-control studies in which questions regarding night shift work have focused on one specific pattern, ${ }^{12}{ }^{13}$ although since long-term night shift work was a rare exposure in this study, it was not possible to stratify analysis between rotating and permanent night shift patterns. One recent nested case-control study found increased risk of breast cancer among nurses who worked at least 5 years in shift patterns that involved a minimum of six or seven consecutive night shifts. ${ }^{15}$ A limitation of the current study was the absence of information concerning the number of consecutive night shifts in each job, such that a similar analysis could not be performed.

Overall, this study observed few pronounced differences in the association of night shift work with breast cancer risk when stratified by menopausal status, although the OR for those in the $\geq 30$ years night shift work category was smaller than in the overall analysis, and no significant relationships between night shift work and breast cancer were observed among premenopausal women. These results are fairly similar to previous work, ${ }^{12-14}$ where results for postmenopausal women from a 
Table 4 Shift work by hormone receptor status

\begin{tabular}{|c|c|c|c|c|c|c|c|c|}
\hline \multirow[b]{2}{*}{ Years shift work history* } & \multirow{2}{*}{$\begin{array}{l}\text { Controls }(n=1179) \\
n(\%)\end{array}$} & \multicolumn{3}{|c|}{$E R / P R+(n=840)$} & \multicolumn{3}{|c|}{$E R / P R-(n=166)$} & \multirow{2}{*}{$\begin{array}{l}\text { Interaction by } \\
\text { ER/PR status } \neq\end{array}$} \\
\hline & & n (\%) & ORt & $95 \% \mathrm{Cl}$ & n (\%) & ORt & $95 \% \mathrm{Cl}$ & \\
\hline None & $773(65.6)$ & $547(65.1)$ & - & - & $116(69.9)$ & - & - & - \\
\hline $0-14$ & $312(26.5)$ & $216(25.7)$ & 1.00 & 0.81 to 1.23 & $37(22.3)$ & 0.78 & 0.52 to 1.17 & $p=0.22$ \\
\hline $15-29$ & $81(6.9)$ & $55(6.6)$ & 0.97 & 0.68 to 1.39 & $11(6.6)$ & 0.90 & 0.47 to 1.75 & $p=0.84$ \\
\hline$\geq 30$ & $13(1.1)$ & $22(2.6)$ & 2.37 & 1.18 to 4.76 & $2(1.2)$ & 1.06 & 0.24 to 4.75 & $p=0.27$ \\
\hline
\end{tabular}

case-control study nested in a Norwegian nursing cohort have suggested an increased risk among those working $\geq 30$ years night shift work and a protective relationship among short-term night shift workers, while among premenopausal women from the same cohort, an elevated OR for long-term night shift workers was suggested. ${ }^{14}$ As well, the Nurses' Health Study, also in nested case-control analysis, has reported increased breast cancer risk for postmenopausal women working $\geq 30$ years rotating night shift work, ${ }^{12}$ and for premenopausal women following $\geq 20$ years rotating night shift work. ${ }^{13}$ Similar to our results, two previous case-control studies saw no differences in the effect of night shift work when considering the effect of tumour ER status alone. ${ }^{12}{ }^{20}$ Melatonin, a proposed intermediate between night shift work and breast cancer, ${ }^{8}$ could influence cancer risk through an impact on oestrogen production, ${ }^{28}$ such that a stronger relationship for ER/PR+ tumours might be expected. While the estimated OR in this study for $\mathrm{ER} / \mathrm{PR}+$ tumours was indeed larger for women with a history of 30 or more years of night shift work, the small number of $\mathrm{ER} / \mathrm{PR}$ cases in this category means we were likely underpowered to detect interactions, such that it is impossible to conclude that this apparent difference represents a true biologic effect.

When classifying night shift work as a 'probable carcinogen' and categorising the evidence from human studies as 'limited', the IARC Working Group noted that a number of existing studies in humans were limited to nurses. ${ }^{5}$ While our study was not limited to nurses, the largest proportion of night shift workers from both the $\geq 30$ years and 15-29 years night shift work groups were in health occupations. However, it is important to note that relationships between night shift work duration and breast cancer risk were similar to those of the main analysis for those employed in both health and non-health occupations. Other studies, like ours, have not considered occupational exposures that could confound the association between night shift work and breast cancer.

The recruitment of cases in Vancouver from the populationbased BC Cancer Registry and controls from screening clinics may have introduced selection bias, as some cases may not have participated in screening and, thus, been ineligible to be included as controls. However, a sensitivity analysis excluding all cases from Vancouver who were unlikely to have participated in screening produced similar results to the overall analysis, suggesting the influence of any potential selection bias on study results would be small. Although there were differences in the characteristics of cases and controls, for instance in ethnicity, education and so on, none of these factors were identified as confounders of the night shift work/breast cancer association. Further, modest response rates in both Vancouver and Kingston also create the possibility of response bias in this study. However, in order to bias results, study participation would need to be related to both night shift work and breast cancer risk, and this is unlikely given the manner in which night shift work was assessed. Finally, since study participants were asked to report their occupational history retrospectively, there is the potential for recall bias if the accuracy with which information concerning night shift work exposure was reported were different in the case and control groups. However, given that many exposures in addition to night shift work were assessed in this study, and that at the time of data collection night shift work was not widely recognised as a breast cancer risk factor, it is

Table 5 Industry of shift work jobs

\begin{tabular}{|c|c|c|c|c|}
\hline \multirow[b]{2}{*}{ Industry } & \multicolumn{4}{|c|}{ Years shift work history } \\
\hline & $\begin{array}{l}\geq 30 \\
\mathrm{n}(\%)\end{array}$ & $\begin{array}{l}15-29 \\
n(\%)\end{array}$ & $\begin{array}{l}0-14 \\
\text { n (\%) }\end{array}$ & $\begin{array}{l}\text { None } \\
\text { n (\%) }\end{array}$ \\
\hline Management occupations & - & $1(0.7)$ & $10(1.7)$ & $11(0.7)$ \\
\hline Business, finance and administrative occupations & $1(2.4)$ & $10(6.5)$ & $29(4.9)$ & $243(16.0)$ \\
\hline Natural and applied sciences and related occupations & - & $3(2.0)$ & $11(1.9)$ & $64(4.2)$ \\
\hline Health occupations & $18(43.9)$ & $63(41.2)$ & $110(18.6)$ & $156(10.2)$ \\
\hline Occupations in social science, education, government science and religion & $9(22.0)$ & $24(15.7)$ & $82(13.8)$ & $449(29.5)$ \\
\hline Occupations in art, culture, recreation and sport & $3(7.3)$ & $11(7.2)$ & $47(7.9)$ & $81(5.3)$ \\
\hline Sales and service occupations & $7(17.1)$ & $31(20.3)$ & $257(43.3)$ & $252(16.6)$ \\
\hline Trades, transport and equipment operators and related occupations & $2(4.9)$ & $4(2.6)$ & $26(4.4)$ & $79(5.2)$ \\
\hline Occupations unique to primary industry & - & $3(2.0)$ & $2(0.3)$ & $15(1.0)$ \\
\hline Occupations unique to processing, manufacturing and utilities & $1(2.4)$ & $3(2.0)$ & $19(3.2)$ & $81(5.3)$ \\
\hline No job & - & - & - & $83(5.5)$ \\
\hline Missing & - & - & $2(0.3)$ & $10(0.7)$ \\
\hline
\end{tabular}


unlikely that the ability to accurately recall past work schedules would be related to case/control status.

While light at night and melatonin have been proposed as one pathway through which night shift work may influence breast cancer, and data from prospective studies has generally supported a protective effect of melatonin on breast cancer, ${ }^{32-36}$ biomarker studies of night work and melatonin are less consistent. ${ }^{37-40}$ A role for other potential mechanisms has been suggested, such as sleep disturbances, clock gene dysregulation or lifestyle differences, ${ }^{7}$ and these should be considered in future work. As well, chronotype may play a role in night shift work/ cancer relationships ${ }^{41}$ but, unfortunately, chronotype was not included in this study questionnaire.

In summary, an association between $\geq 30$ years of night shift work in diverse occupations and breast cancer is supported here, consistent with other studies among nurses. ${ }^{12-14} 16$ As shift work is necessary for many occupations, understanding of which specific shift patterns increase breast cancer risk, and how night shift work influences the pathway to breast cancer is needed for the development of healthy workplace policy.

Acknowledgements We would like to thank Dr Chris Bajdik for his contributions to the study. The authors also thank Dr Linda Warren (Screening Mammography Program of BC), Dr Philip Switzer (Greig Associates), Caroline Speers (Breast Cancer Outcomes Unit, BC Cancer Agency, the BC Cancer Registry), Agnes Bauzon, Alegria Imperial, Betty Hall, Lina Hsu, Maria Andrews and Teresa Pavlin for their assistance with participant recruitment and data collection in Vancouver. We also thank Dr Ross Walker, Dr Ralph George, Celine Morissette, Jane Warner, Hilary Rimmer, Meghan Hamel and Annie Langley for assistance with participant recruitment and data collection in Kingston.

Contributors The case-control study described in this manuscript was designed and conducted by KJA, JJS, Chris Bajdik, Angela Brooks-Wilson, HR, IB, Pierre Ayotte, CL, SKS and ASL. Design of the shift work analysis, statistical analysis, interpretation of results and manuscript writing was performed by $A G$ with supervision from KJA and JJS, with feedback from IB, HR, CL, SKS, ASL and DL.

Funding Funding for this study was provided by a grant from the Canadian Institutes of Health Research (Funding Reference \#: 69036). Anne Grundy was supported by a Doctoral Research Award from the Canadian Institutes of Health Research.

\section{Competing interests None.}

Ethics approval Ethical approval for this study was provided by both the University of British Columbia, BC Cancer Agency Research Ethics Board and the Queen's University Health Sciences Research Ethics Board.

Provenance and peer review Not commissioned; externally peer reviewed.

\section{REFERENCES}

1 Wang X-S, Armstrong MEG, Cairns BJ, et al. Shift work and chronic disease: the epidemiological evidence. Occup Med (Lond) 2011;61:78-89.

2 Megdal SP, Kroenke CH, Laden F, et al. Night work and breast cancer risk: a systematic review and meta-analysis. Eur I Cancer 2005;41:2023-32.

3 Erren TC, Pape HG, Reiter RJ, et al. Chronodisruption and cancer. Naturwissenschaften 2008:95:367-82.

4 Kolstad HA. Nightshift work and risk of breast cancer and other cancers-a critical review of the epidemiologic evidence. Scand I Work Environ Health 2008;34:5-22.

5 Straif K, Baan R, Grosse Y, et al. Carcinogenicity of shift-work, painting, and fire-fighting. Lancet Oncol 2007;8:1065-6.

6 WHO. IARC Monographs on the Evaluation of Carcinogenic Risks to Humans: Painting, Firefighting, and Shiftwork. Vol 98. 2010. http://monographs.iarc.fr/ENG/ Monographs/vol98/index.php

7 Fritschi L, Glass DC, Heyworth JS, et al. Hypotheses for mechanisms linking shiftwork and cancer. Med Hypotheses 2011:77:430-6.

8 Stevens RG. Electric power use and breast cancer: a hypothesis. Am J Epidemiol 1987;125:556-61.

9 Lewy AJ, Cutler NL, Sack RL. The endogenous melatonin profile as a marker for circadian phase position. J Biol Rhythms 1999;14:227-36.

10 Davis S, Mirick DK, Stevens RG. Night shift work, light at night, and risk of breast cancer. J Natl Cancer Inst 2001;93:1557-62.

11 Hansen J. Increased breast cancer risk among women who work predominantly at night. Epidemiology 2001;12:74-7.
12 Schernhammer ES, Laden F, Speizer FE, et al. Rotating night shifts and risk of breast cancer in women participating in the nurses' health study. J Nat/ Cancer Inst 2001:93:1563-8.

13 Schernhammer ES, Kroenke $\mathrm{CH}$, Laden $\mathrm{F}$, et al. Night work and risk of breast cancer. Epidemiology 2006;17:108-11.

14 Lie J-A, Roessink J, Kjaerheim K. Breast cancer and night work among Norwegian nurses. Cancer Causes Control 2006:17:39-44.

15 Lie J-AS, Kjuus H, Zienolddiny S, et al. Night work and breast cancer risk among Norwegian nurses: assessment by different exposure metrics. Am J Epidemiol 2011:173:1272-9.

16 Hansen J, Stevens RG. Case-control study of shift-work and breast cancer risk in Danish nurses: Impact of shift systems. Eur I Cancer 2012;48:1722-9.

17 Knutsson A, Alfredsson L, Karlsson B, et al. Breast cancer among shift workers: results of the WOLF longitudinal cohort study. Scand I Work Environ Health 2012;38:336-43

18 Hansen J, Lassen CF. Nested case-control study of night shift work and breast cancer risk among women in the Danish military. Occup Environ Med 2012;69:1-7.

19 Menegaux F, Truong T, Anger A, et al. Night work and breast cancer: a populationbased case-control study in France (the CECILE study). Int I Cancer 2012;132:924-31.

20 O'Leary ES, Schoenfeld ER, Stevens RG, et al. Shift work, light at night, and breast cancer on Long Island, New York. Am J Epidemiol 2006;164:358-66.

21 Schwartzbaum J, Ahlbom A, Feychting M. Cohort study of cancer risk among male and female shift workers. Scand I Work Environ Health 2007;33:336-43.

22 Pesch B, Harth V, Rabstein S, et al. Night work and breast cancer-results from the German GENICA study. Scand I Work Environ Health 2010;36:134-41.

23 Pronk A, Ji B-T, Shu X-O, et al. Night-shift work and breast cancer risk in a cohort of Chinese women. Am J Epidemiol 2010;171:953-9.

24 Stevens RG, Hansen J, Costa G, et al. Considerations of circadian impact for defining "shift work" in cancer studies: IARC Working Group Report. Occup Environ Med 2011:68:154-62.

$25 \mathrm{Ma} \mathrm{H}$, Bernstein L, Pike MC, et al. Reproductive factors and breast cancer risk according to joint estrogen and progesterone receptor status: a meta-analysis of epidemiological studies. Breast Cancer Res 2006;8:R43.

26 Rosenberg LU, Einarsdóttir K, Friman El, et al. Risk factors for hormone receptor-defined breast cancer in postmenopausal women. Cancer Epidemiol Biomarkers Prev 2006;15:2482-8.

27 Phipps Al, Li Cl. Breast cancer biology and clinical characteristics. In: Li C.ed. Breast cancer epidemiology. New York, NY: Springer New York, 2010:21-46.

28 Cos S, González A, Martínez-Campa C, et al. Estrogen-signaling pathway: a link between breast cancer and melatonin oncostatic actions. Cancer Detect Prev 2006:30:118-28.

29 Canada S. Classification for Statistics (NOC-S). 2006. http://www.statcan.gc.ca/pub/ 12-583-x/12-583-x2007001-eng.pdf

30 Friedenreich CM, Courneya KS, Bryant HE. Influence of physical activity in different age and life periods on the risk of breast cancer. Epidemiology 2001;12:604-12.

31 Greenland S, Rothman KJ. Introduction to stratified analysis. In: Rothman K, Greenland S.eds. Modern epidemiology. 2nd edn. Philadelphia: Lippincott-Raven, 1998:253-79.

32 Schernhammer ES, Hankinson SE. Urinary melatonin levels and breast cancer risk. I Natl Cancer Inst 2005:97:1084-7.

33 Schernhammer ES, Berrino F, Krogh V, et al. Urinary 6-sulfatoxymelatonin levels and risk of breast cancer in postmenopausal women. J Natl Cancer Inst 2008;100:898-905.

34 Schernhammer ES, Hankinson SE. Urinary melatonin levels and postmenopausa breast cancer risk in the Nurses' Health Study cohort. Cancer Epidemiol Biomarkers Prev 2009:18:74-9.

35 Travis RC, Allen DS, Fentiman IS, et al. Melatonin and breast cancer: a prospective study. J Natl Cancer Inst 2004;96:475-82.

36 Schernhammer ES, Berrino F, Krogh V, et al. Urinary 6-Sulphatoxymelatonin levels and risk of breast cancer in premenopausal women: the ORDET cohort. Cancer Epidemiol Biomarkers Prev 2010;19:729-37.

37 Schernhammer ES, Rosner B, Willett WC, et al. Epidemiology of urinary melatonin in women and its relation to other hormones and night work. Cancer Epidemiol Biomarkers Prev 2004;13:936-43.

38 Schernhammer ES, Kroenke CH, Dowsett M, et al. Urinary 6-sulfatoxymelatonin levels and their correlations with lifestyle factors and steroid hormone levels. J Pineal Res 2006:40:116-24.

39 Nagata C, Nagao Y, Yamamoto $S$, et al. Light exposure at night, urinary 6-sulfatoxymelatonin, and serum estrogens and androgens in postmenopausal Japanese women. Cancer Epidemiol Biomarkers Prev 2008;17:1418-23.

40 Grundy A, Tranmer J, Richardson $\mathrm{H}$, et al. The influence of light at night exposure on melatonin levels among Canadian rotating shift nurses. Cancer Epidemiol Biomarkers Prev 2011;20:2404-12.

41 Kantermann T, Juda M, Vetter $C$, et al. Shift-work research: Where do we stand, where should we go? Sleep Biol Rhythms 2010;8:95-105.

42 Burch J, Wirth M, Steck S, et al. Circadian disruption indicators and breast cancer risk among women in India. Epidemiology 2012;(5S):S203. 